clinical studies or writing reviews, who take the easy way, do too little work too quickly, because they know the X Journal will always publish it. Yet with a bit more effort and self-discipline they were capable of doing work properly, getting it into a proper journal, and even contributing to psychiatric practice instead of to the rubbish mountain. As an ex-editor (over $\mathbf{4 0}$ years!) I think one may be able to avoid this pitfall, but it means a great deal of editorial work, which I don't see in issue no. 1.

Take your 'Invited Review', for instance. It isn't a review, its a sort of annotation or leaderette, and it reads to me confused. Phil Seager is an old friend of mine, and I admire as well as like him. He's obviously pretty busy as Director of the HAS, and worried by its problems, and here he seems to be asking himself two questions and not finding the answers (1) What is a medical model and is it ever appropriate - if so, how far? (2) When is a client a patient, and vice versa? These are two important questions, I think you should have (a) got the text clarified (b) invited a social worker, a nurse, a psychologist to give their views at the same time, made it a stimulating discussion with clear pros and cons.

This raises another point. Is the new journal just for psychiatrists or for all members of the team? There might be a place for a truly interprofessional journal, explaining each to the others. I know you have a non-medical contribution on a community mental health centre; it could have been so much more informative to the medical reader with some editorial guidance.

The history of Mendip Hospital, Wells, contains interesting material, but why no guidance on where to read more about it, or how to study the history of one's own hospital (e.g. see Annual Reports); why no comparison with what has been written about other hospitals (Psychiatry for the Poor by Hunter \& Macalpine, Dawsons (1974), Museums of Madness by Andrew Scull, Penguin (1982), etc); why stick to the amusing anecdote instead of educating? Asylum histories can teach old answers to current problems of how to run a mental health service.

Your remark about the geography of the southwest requiring a special journal to bring psychiatrists together puzzles me. Why won't the Psychiatric Bulletin or the British Journal of Psychiatry do? Is there something special about the rural schizophrenics of Dartmoor or the psychopaths of Torquay which we in the rest of Britain won't understand? Or are you planning advertisements of the type "young Cornish psychiatrist would like to meet similar with view to companionship and study for membership"?

I think your plan to encourage single case reports by registrars, and critical literature reviews by nonconsultants is in principle excellent, and could be a real addition to training. But to be any use I am sure much editorial guidance will be needed: getting full but only relevant information in the cases; choosing subjects for the reviews and suggesting questions for answer in them to prospective authors, as well as revision at the end.

Of course it's not fair to judge anything on the first issue. I criticise because I want you to succeed, it's a way of wishing you well. A committee can't produce a good journal, it has to be a positive expression of one person's outlook and taste: as Eliot Slater, Cyril Connolly and others testify.

Emeritus Reader in Biological Psychiatry

JOHN CRAMmer

Institute of Psychiatry

London SE5

\section{DEAR JOHN}

Thank you for your letter about the first number of South West Psychiatry. You have taken much trouble to give us valuable advice based on your extensive experience as an editor, and we are most grateful for your guidance. There are several points on which I am keen to reply.

You clearly are concerned that we might merely encourage material of poor standard, thereby adding to the 'rubbish mountain'. Our Editorial Board is very mindful of such a danger, and has no intention of wasting its time, or that of its readers, by promoting the publication of low quality papers. Let me point out the role that we envisage for our Journal; it is spelt out in our first number, but it seems that you are not entirely clear on this point which certainly is not made apparent in your letter.

South West Psychiatry is intended to have a local circulation within the South West Region. One of its main aims is to stimulate trainee psychiatrists to begin thinking critically about their work, and to express this in writing. Are you not worried, after $\mathbf{4 0}$ years as editor, about the reluctance which many trainees show in taking the very first steps in this direction? Do you not share my concern that psychiatric training is at risk of merely encouraging the absorption of facts and subsequent application of given truths? South West Psychiatry will try to act as a catalyst at a very early stage, without claiming copyright, in the hope that trainees might submit preliminary reports and abstracts to us, and then subsequently develop their ideas further for submission of papers to a national journal. The current editor of the British Journal of Psychiatry has in fact welcomed this approach.

The role of South West Psychiatry throughout our Region also needs comment. Your quip about trainees in Cornwall getting together is touching but nearer the truth than you might realise. Now that services have been sectorised, clinical psychiatry can be a lonely business. As someone who travels the length of the South West Region more regularly than 
most, I am concerned at the need to maintain morale and a sense of identity amongst psychiatrists at a time when their role is under fierce challenge. We hope that South West Psychiatry will help by fostering their sense of common identity and purpose.

One last point concerning your comment on Philip Seager's article, inevitably brief but crystal clear to us, though not to you. It might interest you to know that widespread interest and discussion has been stimulated by this particular paper, and we believe it achieved its primary aim splendidly.

Let us now give South West Psychiatry a fair trial without further ado, shall we?

\section{Department of Mental Health} University of Bristol

\section{H. Gethin MORGAN}

The Evaluation of Quality of Life in the Community: E QUAL: C Individual Recording Booklet and E QUAL: G Group Recording Booklet.

By M. Harris, Huddersfield Health Authority. Enquiries: Unit General Manager, Huddersfield Health Authority, Storthes Hall Hospital, Kirkburton, Huddersfield.

Several large-scale quality of life (QOL) surveys have been carried out since the mid 1970 s to determine the subjective and objective assessments of the American way of life. Collecting comparable information from chronic mental patients living in community residential units was shown to be feasible by Lehman et al (1982). Such patients tend to be single, unemployed and disabled by symptoms; they are often poor and have little contact with others. These features were mirrored in the main areas of QOL dissatisfaction: finance, unemployment, health, relationships and personal safety. It was also noted that there was discrepancy between objective and subjective assessments; living conditions which satisfied over half of the residents appeared to be undesirable by the average American.

This publication comprises two complementary booklets aimed at assessing the QOL in community residential units. E QUAL: $C$ covers the main $Q O L$ items for individual residents. It also includes ratings of the individual's sense of autonomy and involvement in future plans. Discrepancies between the resident's perception and the rater's assessment are noted. A summary and recommendations for further action are made and results of subsequent interventions are recorded at a follow-up interview.

E QUAL: $G$ sums up the information culled from the individual booklets to compile a profile of the residential unit in order to assist future planning.

The ratings should go a long way towards achieving the intended aims: however, their value would be augmented by a predetermined cycle of periodic re-assessments. It should be remembered, however, that the translation of QOL questions into measurable terms remains problematic (Lehman et al. 1982).

Consultant Psychiatrist

MOUNIR EKDAWI

Netherne Rehabilitation Service, Coulsdon

Surrey

\section{Reference}

Lehman, A. F., WARD, N. C. \& LinN, L. S. (1982) Chronic mental patients; the quality of life issue. American Journal of Psychiatry, 139, 1271-76.

Examination Techniques in Psychiatry.

By N. L. Holden, London: Hodder \& Stoughton. 1987. Pp.45. £2.50.

This booklet attempts to help the MRCPsych candidate improve his or her examination techniques. The book covers six chapters and includes advice on writing essays, multiple choice questions, short answer questions, clinical examination, preparing for the clinical assessment, management and prognosis and the oral examination.

The first chapter on essays seems to state the obvious; one should present a clear, concise, structured and factual answer to the question asked. The MCQ chapter mainly focuses on knowing one's own level of guessing - whether one is almost certain or choosing at random. The need for a logical structured and comprehensive answer to short questions is underlined in the SAQ chapter. The examples given clearly make the point that comprehensiveness coupled with good factual knowledge is the goal to aim for. In the fourth chapter useful hints are offered to the candidate to help him or her organise the time during the interview with the patient. One also gets interesting fashion hints and advice on etiquette! The chapter on assessment and management also makes interesting reading and again advises on clear, concise and confident presentations. Useful hints on organising aetiological factors appear, but it is notable that caution is advised on psychodynamic assessments. The last chapter on oral examinations gives good simple advice - "don't waffle".

Most of the content of this booklet I would expect most candidates to have already assimilated, particularly from colleagues who have done the examination or from tutors. It may be useful for candidates who have not got close contact with registrars of a similar level or who have difficulty in passing the examination. It would also be useful to read as good common sense on the night before the examination to calm the nerves and it is cheap!

Consultant Psychiatrist

E. Gilvarry

St Nicholas Hospital

Newcastle upon Tyne 